IZA DP No. 9916

Identifying National Level Education Reforms in Developing Settings: An Application to Ethiopia

Luke E. Chicoine

April 2016 


\title{
Identifying National Level Education Reforms in Developing Settings: An Application to Ethiopia
}

\author{
Luke E. Chicoine \\ DePaul University \\ and IZA
}

Discussion Paper No. 9916

April 2016

IZA
P.O. Box 7240
53072 Bonn
Germany

Phone: +49-228-3894-0

Fax: +49-228-3894-180

E-mail: iza@iza.org

Any opinions expressed here are those of the author(s) and not those of IZA. Research published in this series may include views on policy, but the institute itself takes no institutional policy positions. The IZA research network is committed to the IZA Guiding Principles of Research Integrity.

The Institute for the Study of Labor (IZA) in Bonn is a local and virtual international research center and a place of communication between science, politics and business. IZA is an independent nonprofit organization supported by Deutsche Post Foundation. The center is associated with the University of Bonn and offers a stimulating research environment through its international network, workshops and conferences, data service, project support, research visits and doctoral program. IZA engages in (i) original and internationally competitive research in all fields of labor economics, (ii) development of policy concepts, and (iii) dissemination of research results and concepts to the interested public.

IZA Discussion Papers often represent preliminary work and are circulated to encourage discussion. Citation of such a paper should account for its provisional character. A revised version may be available directly from the author. 
IZA Discussion Paper No. 9916

April 2016

\section{ABSTRACT}

\section{Identifying National Level Education Reforms in Developing Settings: An Application to Ethiopia}

Increasing enrollment in primary education has been at the center of international education policy for well over a decade. In developing parts of the world, significant increases in primary enrollment are often generated by large national level programs, which can simultaneously promote overcrowding and reductions in education quality. However, to analyze the trade-off between increased enrollment and potential reductions in quality one must first identify and evaluate the impact of the national reform on schooling. This paper provides a method with which these types of reforms can be identified in developing settings using both temporal and geographic variation, and readily available data. The method is applied to an early 1990s reform in Ethiopia based around the release of the Education and Training Policy, which removed schooling fees from grades one to ten. The model estimates that the reform led to an increase in schooling of at least 1.2 years, and provides initial evidence that the increased enrollment in Ethiopia outweighed any cost due to reductions in quality.

JEL Classification: $\quad$ I25, I28, 055

Keywords: free primary education, Ethiopia, schooling

Corresponding author:

Luke Chicoine

Department of Economics

DePaul University

1 East Jackson Blvd, Suite 6200

Chicago, IL 60604

USA

E-mail: Ichicoin@depaul.edu 


\section{Introduction}

According to the World Bank's World Development Indicators, 40 percent of primary age children in SubSaharan Africa were out of school in the year 2000; a ten percentage point improvement relative to 1990. This was not a problem that went unnoticed. In the 1990's there were three major national initiatives to provide free primary education (FPE) in Ethiopia, Malawi, and Uganda (Deininger, 2003). The second Millennium Development Goal of universal primary education reinforced these efforts, and at least 15 countries additional implemented their own FPE reforms since the turn of the millennium. Data from the OECD's International Development Statistics database show that donor countries and organizations joined the effort and official development assistance for basic education doubled in the decade leading up to 2010. The goal of these efforts was to get students into the classroom, and in the year following the reforms, grade one enrollment increased an average of 25 percent over the previous year (UNESCO Institute for Statistics). Continuous effort and focus is required to maintain a consistent quality of education in the face of such large increases in enrollment. On average, the year after the reform came into effect, pupil-teacher ratios increased 10 percent, and possibly more troublesome, by 2014 the initial surge in donor support had already declined 30 percent from peak levels. It is possible that any benefit of these programs generated by the increases in enrollment could be entirely overwhelmed by the potential decline in quality generated by overcrowding and under investment. However, before this question can be answered, it is necessary to be able to identify the effect of a national level reform in a developing setting. This paper develops a technique to identify the effect of a national education reform on schooling attainment using data that are contained in most household datasets. This technique is then demonstrated using an education reform in Ethiopia from the early 1990s, and applied to three separate sources of data.

Building on the framework of Lucas and Mbiti (2012a,b), this paper focuses on the construction of a method that can quantify the potential magnitude of national level reforms at any level of education using both the geographic and temporal variation. This method is then applied to the removal of school fees in Ethiopia. The effect of the reform on years of schooling is estimated using three different post-reform data sources: the 2007 round of the census, 2005 and 2011 rounds of the Demographic and Health Survey (DHS), and the 2014 Living Standards and Measurement Study (LSMS). It is shown that the reform led to an increase of between 1.2 and 1.7 years of schooling, and that the effect was about three-tenths of a

year larger for women. The reform also led to an increase in literacy of over ten percentage points, a 30 percent increase relative to baseline levels, and a higher rate of completion of the post-eighth grade exam. This is suggestive evidence that the increased level of schooling did lead to increased learning, outweighing any potential quality declines. Placebo reform measures are also constructed using data from four countries 
(Kenya, Tanzania, Zambia, and Mali) that did not have an education reform in the 1990s. Placebo estimates for all four countries yield no evidence of large increases in schooling during the same time period; these results help to rule out that the estimates from Ethiopia are capturing any type of secular trend in education.

In developed settings, identification strategies are generally more straightforward, and can exploit the exact letter of the law to identify the effect of education, such as cutoffs in age-at-school-entry dates (McCrary and Royer, 2011), or internal variation in such policies (Elder and Lubotsky, 2009). However, due to issues such as late school entry and high repetition rates, it is more difficult to find and exploit such explicit variation in developing settings, although Agüero and Bharadwaj (2014) and Grépin and Bharadwaj (2015) showed that it is possible. The more common approach has been to exploit two separate dimensions of variation, the timing of the reform and geographic variation in the implementation. For example, Duflo (2001; 2004) used variation in the construction of primary schools to examine the relationship between education and wages in Indonesia, and Osili and Long (2008) exploited similar variation in Nigeria to examine how education impacts fertility. The general policy change in an FPE reform is to remove compulsory school fees in all primary schools across the country (the extent of fee removal varies reform to reform); therefore, there is no geographic variation in the implementation of the reform itself. Previous work examining the impact of malaria eradication exploited pre-intervention levels of the disease to generate variation in the expected impact of the anti-malaria programs (Bleakley, 2010; Lucas, 2010, 2013). The benefit to this type of strategy is that it does not depend on variation in the implementation, but the geographic component of the variation is determined solely on the pre-intervention characteristics of each geographic district. Lucas and Mbiti (2012a,b) applied a similar strategy using variations in pre-reform primary completion rates to generate geographic variation. They examined the effect of the 2003 FPE reform in Kenya on gender differences in schooling and sorting into private schools.

This paper evaluates a central component to education reform in Ethiopia, the removal of school fees in grades one through ten. Data from the 1994 Ethiopian census are used to estimate the level of expected impact of the reform separately for each of the 60 zones (i.e. counties) across Ethiopia. The estimated effect of the reform in each specific zone is assumed to be inversely related to the education level of pre-reform birth cohorts. The removal of school fees is expected to have a greater impact on areas that have relatively lower initial levels of education. These zone-specific measures are then interacted with the timing of the reform and zone-specific data on school starting age to calculate the maximum intensity with which the reform could have affected an individual born in a specific year in a specific zone. This provides both geographic and temporal variation that is used to identify the effect of the reform. It is important to note that the method that is described in this paper requires only pre-reform information regarding the fraction of the population completing each year of schooling and starting at each age at some subnational level. This can 
then be matched with the birth year (or age) and the location of respondents from a post-reform survey, and the full effect of the national education reform estimated. In Ethiopia, the reform is found to have led to a significant increase in schooling. The estimates are not sensitive to changes in the sample, or alternative assumptions in the calculation of the intensity measure. Although precise zone of birth is not available, three alternative strategies using region (i.e. state or province) of birth information in the LSMS find similar estimates to the baseline model. Furthermore, 86 percent of respondents in the LSMS sample live in their region of birth. Importantly, this method only finds an increase in schooling in Ethiopia, and does not capture secular increases in education in four alternative countries from Sub-Saharan Africa.

The relevant history of Ethiopia and the education reform is outlined in Section 2. The estimation of the potential magnitude of the reform's impact, and the combination of this measure with the timing of the reform's implementation is described in Section 3. The data is summarized in Section 4, along with the paper's estimating model. The estimated effect of the reform on years of schooling in Ethiopia is explored in Section 5. The paper is concluded in Section 6.

\section{Background and Education Reform}

Beginning in 1974 Ethiopia was governed by a military council, a period that was briefly followed by four years of a single party communist rule, which ended in 1991 (Ofcansky and Berry, 1993). Under these governments, students entered school at age seven, a starting age that remains unchanged today, primary school lasted six years, junior secondary school two years, and senior secondary four years (World Bank, 2009). Grade 1 enrollment declined roughly 25 percent between 1979 (first year of available data) and the fall of the communist government, and the fraction of the national budget spent on education fell nearly 50 percent (Oumer, 2009). During this time period, there was no set tuition fee charged for school attendance; however, public primary and secondary schools often imposed per-student fees to cover the cost of attendance. Fees were significantly lower in government run schools, and these schools educated more than 90 percent of primary school students (World Bank, 2009). ${ }^{1}$

In 1991, the Ethiopian Peoples Revolutionary Democratic Front took power and moved quickly to establish a transitional government and decentralize authority. The transitional government established nine regional governments and two independent administrative councils in the country's two largest cities. These 11 regions were largely set up along historical ethnic lines, elected their administrations in the summer of 1992, and each have their own independent Education Bureau. The decentralization of education policy in Ethiopia occurred through two main declarations. The first was Proclamation No. 41 of 1993. This

\footnotetext{
${ }^{1}$ All statistics are from the World Bank's World Development Indicators, and the UNESCO Institute for Statistics.
} 
proclamation clarified the division of power between central and regional authorities. Following this proclamation, the regional authorities became responsible for the administration and provision of primary and secondary education. This proclamation functioned as the "cornerstone" for the education policy that was being drafted, and acted as the de facto initial implementation of the forthcoming policy. The official Education and Training Policy, the second major education declaration, was eventually published in 1994, and was officially forwarded to the regional governments prior to the 1995 school year. The key aspect of this proposal was that it required that education be fee-free for grades one through ten. The decentralization of power and lack of official fees in place slowed the implementation of this policy in some areas, but by 1996 a majority of the country had complied with the decree (Negash, 1996; UNESCO, 2007; Oumer, 2009; World Bank, 2009). ${ }^{2}$ This reform is unlikely to have made school "free" for all students, in fact, the government acknowledged that community support remained an important part of financing education, but schools were no longer allowed to request a per-student fee (Oumer, 2009; World Bank, 2009). Falling short of fully removing the cost of attending school only makes finding an impact of the policies more difficult to identify; therefore, what is directly being measured is the effect of the intention of the government to remove school fees. Additionally, the Education and Training Policy extended the length of primary school to eight years, with an additional two years in both junior and senior secondary school. Importantly, there is a cutoff after eight years of schooling in both the pre and post reform periods, this will be exploited later in the paper.

Enrollment data from the UNESCO Institute for Statistics can be used to determine whether there is initial evidence that the two reforms issued by Ethiopia's central government impacted school attendance. Grade one enrollments are likely to be the most responsive to the fee reductions; it is at this margin there are the largest number of students who could potentially be affected by the reform. The initial impact of Proclamation No. 41 should first be seen in the 1993 school year, and the impact of the Education and Training Policy in the 1995 academic year. Grade one enrollments are shown in Figure 1 from 1979, the first year data are available, to $1999 .^{3}$ In the 14 years leading up to 1993, and Proclamation No. 41, grade one enrollment was relatively flat. The number of primary school entrants had actually declined by nearly 20 percent from 1979 levels, and roughly 40 percent from peak levels. The fall in the late 1980s coincides with the conflict that eventually led to the overthrow of the military government. ${ }^{4}$ The 1993 and 1995

\footnotetext{
${ }^{2}$ Proclamation No. 41 also enabled regions to teach in local languages. Zenebe Gebre (2014) finds that the introduction of mother tongue education actually had a significant negative impact on enrollment, negative 6 percentage points, and schooling, a reduction of 0.4 years of school. This downward pressure on schooling should only make it more difficult to find a positive impact of fee-free schooling.

${ }^{3}$ Ethiopia uses their own calendar that begins its new year, and new academic year, around the second week of the Gregorian (Western) September. The numerical Ethiopian year is either seven or eight months behind the Gregorian year, depending on the month. The year referenced in the text is the Gregorian year in which the academic year began. For example, 1993 references the 1993 to 1994 academic year that began in September of 1993.

${ }^{4}$ Note that the timing of reform implementation that will be identified in this paper occurs differentially across the country between two and five years following the end of the armed conflict, suggesting that the peace that saw the Ethiopian Peoples Revolutionary Democratic Front take power is an unlikely explanation for the papers findings.
} 
school years represent the two largest increases in grade one enrollment both in terms of the number of additional students entering school and in percentage growth. The publication of Proclamation No. 41 is associated with more than 280,000 additional students entering grade one relative to the previous year, a 45 percent increase. Then in 1995, grade one enrollment grew another 317,000 students following the dissemination of the Education and Training Policy, a year-to-year growth of 28 percent. These are the largest two increases in annual enrollment. Between 1992 and 1995 pupil-teacher ratios in primary school increased 40 percent, the increase was more than 60 percent from 1992 to 1996, the year when most of the country had fully implemented fee-free education. The growth in the number of students per school is even greater, growing over 75 percent between 1992 and 1995, and 90 percent through 1996 (Ministry of Education, 1995, 1996, 2000). This is evidence that the increase in enrollment is not being generated by an increase in the supply of education, but an increase in demand driven by the reduced out-of-pocket cost of school. These trends are common following this type of national reform, and often pointed out by critics of these large-scale education reforms. This suggests that Ethiopia conforms to the pattern that is often observed after a country implements a "big-bang" education expansion; large-scale growth in access to education, and an expansion of enrollment that typically outpaces the supply of teachers and classrooms. This is evidence of both the potential effectiveness of these policies, and that Ethiopia is an appropriate context in which to demonstrate a technique to identify and measure the impact of the reform on schooling.

\section{Methodology}

\subsection{Zone Specific Magnitude and Timing}

Quantifying the potential magnitude of the reform is essential to estimating the predicted impact, and doing this separately for each zone in Ethiopia generates the necessary geographic variation. To allow for future cross-country comparisons, the potential magnitude of the reform is calculated in reference to the pre-reform duration of primary school, six years. Motivated by work from Lucas and Mbiti (2012a,b), the underlying concept is that the magnitude of the reform's impact is inversely related to the pre-reform level of schooling. In each zone, $z$, some fraction of students never enter school $\left(F_{z, 0}\right)$, and removing school fees for grades one through ten has a maximum potential impact of ten years of additional schooling for these students. The maximum effect in zone $z$, for this group of students, is then equal to the product of the fraction of students in the zone who never attended school and the maximum potential impact of the reform $\left(10 \cdot F_{z, 0}\right)$. In this district there also exists some fraction of the population that would have dropped out after completing the first grade $\left(F_{z, 1}\right)$, these students received a maximum nine years of additional schooling following the removal 
of school fees $\left(9 \cdot F_{z, 1}\right)$. The same is true for students who would have dropped out after each successive year, following grades two through nine. Students completing at least ten years of school are assumed to be unaffected by the removal of school fees in grades one through ten. Therefore, to capture the magnitude of the maximum potential effect of the reform in zone $z, M_{z}(G)$, the impact must be summed across grade levels zero through nine,

$$
M_{z}(G)=\frac{1}{6} \sum_{g=G}^{9}(10-g) \cdot F_{z, g}
$$

The equation is divided by six to scale the maximum impact of the reform in reference to the original length of primary school, and set $G=0$ to capture the impact of the reform across all grades. As previously stated $F_{z, g}$ is the fraction of the population in zone $z$ that left school following grade $g$, and $(10-g)$ is equal to the number of additional years of schooling they could complete after the removal of school fees. The maximum value of the potential magnitude would occur in a zone where no student attended school prior to the reform $\left(F_{z, 0}=1 ; F_{z, g}=0 \forall g \in[1,9]\right)$; every student would receive ten additional years of schooling. The maximum potential magnitude of the reform is then 10/6. If every student completed at least ten years $\left(F_{z, g}=0 \forall g \in[0,9]\right)$, then the predicted impact of the reform would be zero.

For individuals entering school following the reform's implementation, the reform impacts their schooling decision beginning with whether or not they should enter school at all. They are affected by the full magnitude of the reform, and the $G$ parameter from equation (1) is equal to zero $(G=0)$. However, for students who had completed four years of school when the reform was put into place the removal of school fees would not affect their decision to attended grades one through four, but will impact their decision to drop out after grade four and each subsequent level. For these students, the impact of the reform begins following the fourth grade, and equation (1) is calculated with $G=4 .{ }^{5}$ How the predicted magnitude is assigned to observations from the data is determined by the timing of the reform, and by the respondent's birth year. If every student started on time, at age 7 , it would be straightforward to assign each observation the appropriate magnitude equation. However, the data from Ethiopia, like much of the developing world, show that this is not the case; delayed entry is common.

Zone specific starting age probabilities are calculated for ages 6 to 12. This takes into account the possibility that students enters grade one anytime from one year early, at age six, to five years late, at age $12{ }^{6}$ An intensity measure, $I_{z y}$, is used to appropriately assign the magnitude across birth cohorts. An individual born in 1972 or later, even starting school at age 12, will progress through the tenth grade prior

\footnotetext{
${ }^{5}$ The magnitude equation with $G=4: M_{z}(4)=\frac{1}{6} \sum_{g=4}^{9}(10-g) \cdot F_{z, g}$

${ }^{6}$ Due to high rates of students never entering school in the pre-reform period, the largest margin along which the reform affects schooling is entry into grade one. Although grade repetition occurs, data are not available at the zone level, and the magnitude of its impact on the distribution of the reform's timing is likely to be modest relative to school entry.
} 
to the reform being put into place. Therefore, individuals born in 1972 or earlier will not be affected by the removal of school fees. On the other extreme, the reform will be implemented prior to individuals born in 1989 entering school, even if they enter a year early. All individuals born in 1989 or later are fully impacted by the reform, corresponding to an $M_{z}(0)$ magnitude. This distribution can be seen in the following equation,

$$
I_{z y}= \begin{cases}0 & \text { if } y \leq 1972 \\ \sum_{a=6}^{12} S_{z y a} \cdot M_{z}\left(G_{y+a-7}\right) & \text { if } 1973 \leq y \leq 1988 \\ M_{z}(0) & \text { if } y \geq 1989\end{cases}
$$

The intensity of the reform for individuals from zone $z$, born in year $y$, is denoted $I_{z y}$. As noted above, this is zero for all individuals born in 1972 and before, and the maximum zone specific magnitude, $M_{z}(0)$, for individuals born in 1989 and later. $S_{z y a}$ is the probability of starting school at age $a$, for individuals from zone $z$, and born in year $y$. The intensity of the reform's impact for individuals born between 1973 and 1988 is the sum of a set of seven zone-specific magnitudes weighted by starting age probabilities. To calculate starting age probabilities, data are used to estimate the fraction of grade one entrants at each age, 6 to 12 . Assuming a constant relative relationship across ages, two starting probabilities are calculated. Pre-reform starting probabilities are calibrated to sum to one minus the fraction of students never entering school in each zone, these are assigned to birth year and starting age combinations that would have had to make the decision to enter school prior to the removal of fees. Post-reform starting probabilities are calibrated to sum to one, the maximum impact of every student entering school. The combination of starting age and birth year determines the magnitude equation with which the starting age probability is paired. The starting age probability at age seven for any given birth year $y$ is always paired with the magnitude equation for the same birth year, $S_{z y, 7} \cdot M_{z}\left(G_{y}\right)$. However, the starting age nine probability is then paired with the magnitude equation for the birth cohort born two years later, $S_{z y, 9} \cdot M_{z}\left(G_{y+2}\right)$. These products are calculated for each age, 6 to 12, and then summed together to construct the intensity measure for each birth year from 1973 to $1988 .^{7}$ Finally, the intensity measure is also calculated separately for men and women to allow for sex specific estimates of the reform's impact on schooling.

\subsection{Regional Timing}

As discussed in Section 2, the implementation of the reform is staggered across Proclamation No. 41 (1993), the Education and Training Policy (1995), and possible delayed implementation (1996) due to the

\footnotetext{
${ }^{7}$ For further detail, a table listing the affected grade levels by birth year, additional details regarding starting age calculations, and the explicit equation used to calculate the intensity measure for each birth year are included in the appendix.
} 
decentralized government structure put into place by the transitional government (World Bank, 2009). An objective method is constructed to identify the timing of the reform's implementation in each of the country's 11 regions. Pre-reform (1989 to 1992) regional level enrollment data are used to construct predicted levels of grade one enrollment for the next four years (Ministry of Education, 1995, 1996, 2000). For each region, the annual grade one enrollment level is then compared to the predicted level of enrollment; the post-reform period is set to begin in the year with the largest increase of this relative measure. ${ }^{8}$ To ensure that the estimates seen in the following section are not dependent on this definition of implementation, additional estimates are shown using a staggered implementation of the reform. The estimates that allow for gradual implementation use the same distance above the predicted enrollment level for the years 1993 to 1996, and assume no implementation prior to 1993 and full implementation no later than 1996.

The national capital of Ethiopia, Addis Ababa, does not follow the same pattern of increase as the other regions throughout the country. As seen in Figure 2, the increases in enrollment in 1993 and 1995 are prevalent in the non-Addis Ababa regions of the country, but the same spikes in enrollment do not occur in the capital. In fact, enrollment levels remain relatively consistent throughout this time period. Furthermore, this consistency in enrollment in Addis Ababa holds true for grades one through eight (Ministry of Education, 1995, 1996, 2000). This suggests the possibility that the reform was either not needed, or may not have occurred, in the capital. This is taken into account by setting the intensity measure for Addis Ababa equal to zero; alternative estimates are also shown calculating the normal intensity measure described by equation (2) for the Addis Ababa region.

\section{Data and Estimation}

\subsection{Data}

This study uses individual-level data from three main sources. Ethiopian census data for the years 1994 and 2007 include information on 5 million and 7.4 million Ethiopians, respectively. These data were collected by the Ethiopian Central Statistical Agency, and made available as part of the Integrated Public Use Microdata Series (IPUMS) International by the Minnesota Population Center. Data from the 1994 census are used to construct baseline education levels and starting age probabilities in each zone. Data from the 2007 census are used to estimate the paper's main education results, and are supplemented with data from the 2005 and 2011 rounds of the Demographic and Health Survey (DHS), and the 2014 Living Standards and Measurement Study (LSMS). Each of these datasets includes information that enables household location to be determined

\footnotetext{
${ }^{8}$ For the eleven regions the reforms are set as follows: Tigray 1993, Afar 1993, Amhara 1995, Oromiya 1995, Somalia 1993, Benishangul Gumuz 1993, Southern Nations, Nationalities, and Peoples' Region 1995, Gambella 1993, Harari 1995, Addis Ababa 1995, and Dire Dawa 1996.
} 
at the second administrative level of Ethiopia, the zone. Census data include time consistent definitions of household location within each zone; household zones using the DHS and LSMS surveys are determined by mapping survey cluster GPS location onto maps of zone-level boundaries. ${ }^{9}$ This information is further crossreferenced with recorded cluster location in the LSMS; zones are not explicitly recorded in the Ethiopian DHS. Each dataset also includes information on individual's years of schooling, sex, and age; this is the only information needed to identify and estimate the impact of the reform.

Each of the datasets has a unique set of strengths, and testing that the effect of the education reform can be identified across all of the surveys provides important evidence that the model is capturing a change that occurred in Ethiopia. Although the 2007 census only collects a small amount of information on each individual, it collects the information necessary to measure the impact of the reform on schooling, and includes thousands of observations in every zone. The census and LSMS do not explicitly ask for birth year, it is inferred using the respondent's age and the year of the survey. The DHS explicitly records birth year, cross checks this information with other dates and ages in the survey to correct for errors, and records the depth of the respondent's knowledge of their birth year. Only 73 percent of respondents are able to report their birth year; it is imputed using age information for the remaining respondents. Due to the importance of the timing of when an individual was born to this study, it is extremely beneficial to have a subsample of respondents with information that has a higher likelihood of being accurate. In the census and DHS, the place of one's childhood education is not explicitly known, but region of birth data in the LSMS suggests that today's location is likely a good approximation. Data from the LSMS demonstrates that 86 percent of respondents born between 1972 and 1989 still live in their region of birth. This information is used to show that estimates for the full sample are similar to those for respondents who remain in the region in which they were born. Furthermore, this information is used to adjust for migration in an alternative construction of the identification variable, again yielding similar estimates.

\subsection{Summary Statistics}

Relevant summary statistics, using data from the 2007 census, are shown in Table 1. Data are shown for the 1972 birth cohort, the first entirely pre-reform cohort, and the 1989 birth cohort, the first fully post-reform cohort. These cohorts bookend the range included in the baseline set of estimates in the following sections. The average intensity measure is shown in the first row, for the full sample on the left-hand side of the table, and then separately for men and women. The intensity measure is always zero for the pre-reform 1972 cohort, and larger for women in the 1989 cohort. As can be seen in the second row, education levels in the

\footnotetext{
${ }^{9}$ Matching to map boundaries is done with two sources. Zone level boundaries are obtained from IPUMS International (2015) and the Food and Agriculture Organization GeoNetwork's Global Administrative Unit Layers (GAUL) maps (2016).
} 
pre-reform period are exceedingly low. From an average of about one year of schooling for women born in 1972, to just under three years of schooling for men born in the same year. These low levels of schooling lead to a large potential impact of the reform, and average full intensity estimates of 1.41 and 1.22 for women and men, respectively. Over this time period, education increased for women and men both, an increase of 1.78 years for women, and 0.91 years for men. Because average education rates are so low in the pre-reform period, increasing average years of schooling in this range could have a significant effect on literacy rates. An initial look at the data reinforces this understanding. Early literacy rates were much lower for women in the earlier cohorts (0.21 vs. 0.50), but increased nearly twice as much as the male literacy rate over this time period. In addition to a basic measure of learning, such as the literacy rate, there is consistent growth across the entire sample for the fraction of individuals completing eighth grade (9 percentage points), and a reduced increase in the completion of ninth grade (5 percentage points).

The evolution of the two key variables, years of schooling and $I_{z y}$, are shown in Figure 3. Years of schooling data are plotted using three-year averages taken from the 2007 census. The initial changes in the instrument occur slowly for birth cohorts from 1972 to the early 1980s. In the construction of the intensity measure, all school entrants for these birth cohorts are assumed to be making their school entry decision prior to the reform; therefore, the impact of the reform is entirely dependent on keeping would-be-dropouts in school longer. There is little growth in years of schooling for cohorts through 1980, but the 1981 and 1982 cohorts outpace the predicted change. In the $I_{z y}$ model, the first cohort possibly making their entry decision after the implementation of the reform is the 1982 cohort, entering at age 12. This suggests that expanding the model to consider entrants at older ages would likely not account for the divergence for these birth cohorts. The performance of the model matches key points in the data for the birth cohorts between 1983 and 1989. For example, the large jump priors to the 1983, 1985 and 1987 cohorts. Overall the comparison in Figure 3 demonstrates that the estimated implementation of the reform, as shown by $I_{z y}$, reasonably tracks the observed evolution of schooling in Ethiopia.

\subsection{Estimating Equation}

The central model of this paper examines the relationship between the estimated intensity measure from equation (2), and years of schooling. The model exploits both the geographic and temporal variation built into the construction of the intensity measure to identify gains in schooling from a national level reform in a developing setting. The estimates used in this paper are from an ordinary least squares model that is defined by the equation

$$
Y_{i z y}=\alpha+I_{z y} \beta+\tau_{y}+\delta_{z}+X_{i z y} \theta+\epsilon_{i z y}
$$


The dependent variable is $Y$, generally years of schooling, for individual $i$, born in year $y$, from zone $z$. $\beta$ is the coefficient of interest, and $I_{z y}$ is the zone and birth year specific estimated intensity of the reform which is calculated by exploiting geographic variation in the zone-specific pre-reform education levels, and the timing of the reform. $I_{z y}$ is scaled to equal one when six years of school, the length of pre-reform primary school, are provided free of fees; therefore, $\beta$ can be interpreted as the increase in years of schooling generated by providing free primary education. $\tau_{y}$ is a set of birth year fixed effects that capture any secular changes occurring across Ethiopia in any given year, and $\delta_{z}$ is a set of zone-specific fixed effects capturing any time invariant characteristics that impact schooling. $X_{i z y}$ is a vector of individual level covariates that could include a cubic for age when multiple survey rounds are part of the sample, a dummy for sex when both men and women are included in the sample, or region of birth. It is important that these covariates are either constant over an individual's lifetime or are determined prior to schooling decisions being made. Estimates are weighted using sampling weights provided by the surveys, and standard errors are clustered by zone to allow for within zone correlation (Bertrand et al., 2004).

\section{Results}

\subsection{Baseline Estimates}

Baseline estimates of the effect of the education reform on years of schooling in Ethiopia are shown in Table 2. All nine samples include birth cohorts from 1972 to 1989, the narrowest band of birth cohorts possible that fully captures the reform. The intensity measure $\left(I_{z y}\right)$ is constructed using both male and female observations to estimate the results in Panel A, and using only the respective sex specific data for the estimates in Panel B and Panel C. All nine estimates, using three separate sources of data, find that the reform led to a statistically significant increase in years of schooling. Estimates for the full sample are shown in Panel A; the model estimates that fee-free primary school led to an increase of between 1.121 and 1.767 years of school. Estimating the model separately for both women (Panel B) and men (Panel C) again yields strong evidence of an increase in schooling generated by the reform in Ethiopia.

Three additional observations come from the results seen in Table 2. First, precision of birth year matters. The intensity measure assigned to an observation is partially dependent on the timing of their birth. The DHS survey specifically attempts to accurately measure year of birth information, and flags imputed results. Additionally, the estimates in column (2) include only individuals that were able to identify their year of birth. ${ }^{10}$ Estimates for the DHS sample are generally larger, suggesting that measurement error in the year of

\footnotetext{
${ }^{10}$ Of the DHS sample, 73 percent are able to report their year of birth information. Estimates using the full DHS sample are included in Appendix Table A2.
} 
birth may be biasing results towards zero. Although larger, this is a reason to think that the DHS estimates may be more accurate. The second observation is that the gender patterns observed in the first two columns, for the census and DHS, are very similar, and match the ex-ante expectation based on the growth in means of years in schooling seen in Table 1. The estimate for the overall sample from the LSMS is similar to the other two sources; however, caution is warranted when interpreting the breakout by gender. Finally, F-statistics are shown for all nine estimates in the table. Although developing this straightforward identification is an important addition to the literature, this method can be useful beyond its applications to measuring the impact of education reforms if the identification is strong enough to be used as an instrument in a two-stage least squares model. The F-statistics shown in Table 2 demonstrate that the intensity measure would be a strong instrument when using the full sample from any of the three datasets, and for any of the three gender breakouts when using the DHS. This suggests that this method, when studying Ethiopia, can be used to examine how education affects any number of important outcomes.

Using the full sample, estimates in Table 3 demonstrate that the results are not dependent on sample selection or key assumptions made in the construction of the intensity measure. Estimates in Panel A expand the birth cohorts included in the sample by an additional three years in either direction. Estimates in Panel B include a fully calculated intensity measure for Addis Ababa. The estimates in Panel C utilize a reconstructed intensity measure that allows for the possibility that the policy was implemented over time, between 1993 and 1996. The pace of implementation is calculated relative to the predicted enrollments levels from section 3.2, and calculated separately for each region. Across all three panels and datasets, the estimates remain statistically significant at the 99 percent level for eight of the nine estimates. This demonstrates that the estimates from Table 2 are not reliant on the specific assumptions used to construct the intensity measure, or the sample range employed.

\subsection{Migration Adjustments}

Of the three data sources used to test the robustness of the intensity measure, the LSMS adds significant value due to its inclusion of birth region information. An intensity measure constructed using zone of birth data would be ideal. However, LSMS data provide evidence that internal migration is not overly prevalent during this time period; more than four-fifths of the sample lives in their region of birth. In addition to this, Ethiopia is divided across strong ethnic and linguistic divides that provide an additional barrier to movement. Important information available from the LSMS can still be used to examine whether internal migration may be biasing the previous estimates. Estimates shown in Table 4 are all generated using the full sample of LSMS data. Estimates in column (1) simply add a set of region of birth fixed effects to the 
original model. The estimates in column (2) include only individuals who remain in their region of birth, 86 percent of the sample. The estimates in the third column utilize a migration adjusted intensity measure. To construct this new measure, province level intensity calculations were made following the same process described in section 2, and allocated using the following three rules: (1) the intensity value is birth zone if zone of birth is a major urban zone (Addis Ababa, Harari, or Dire Dawa), (2) value is region of birth average if currently living in a major urban zone that is not zone of birth, or if living in zone that does not border region of birth, (3) value is original $I_{z y}$ if living in region of birth or zone bordering region of birth. ${ }^{11}$ All three estimates remain statistically significant, and very similar to the baseline estimate from column (3) of Panel A in Table 2. The largest difference is a reduction of one-tenth of one year of schooling, in column (2) of Table 4. The F-statistics also remain above ten for the two estimates that include the full sample. This is evidence that it is unlikely that the estimates from the previous tables are being biased by misallocation of the intensity measure due to migration within Ethiopia.

\subsection{Literacy and Advancing to Grade 8 and Grade 9}

A consistent point of contention regarding this type of "big-bang" reform is that while it may improve the quantity of education provided, it has a detrimental impact on the quality. This sentiment is likely true, but positive changes generated by bringing new students to the classroom may outweigh reductions in quality to the existing education. Literacy can be used to test whether the increase in years of schooling found in the previous results led to increased levels of education. Especially at the lower levels of education seen in the pre-reform period, it seems that increasing schooling off a pre-reform base of two years could potentially lead to large increases in literacy. Estimates using literacy as the dependent variable in equation (3) are shown in Panel A of Table 5. They estimate that the reform led to an increase in the literacy rate of between 8.6 and 12.6 percentage points, and all three estimates are statistically significant. ${ }^{12}$ These results are roughly a 30 percent increase in the literacy rate compared to the baseline level of the 1972 cohort. ${ }^{13}$ This is initial suggestive evidence that the post-reform quality of education remained high enough to lead to a significant increase in learning that would have not otherwise occurred.

An additional way to examine this question of education quality is to exploit a characteristic of the reform in Ethiopia. Progression past grade eight required completion of an exam both before and after the reform. This provides a second setting in which the quantity-quality balance can be seen and evaluated. The

\footnotetext{
${ }^{11}$ Rule 1 is prioritized, and Rule 2 is prioritized over Rule 3. Note that Addis Ababa, Harari, and Dire Dawa function as both zones and regions. If born in these regions, then zone-specific intensity measure is known for zone of birth.

${ }^{12}$ Marginal probit estimates are larger for all three datasets ranging from 0.117 to 0.15 , and remain statistically significant at the 99 percent level for the census and DHS, and at the 90 percent level for the LSMS.

${ }^{13}$ Literacy rate estimates for the female sample are above 0.1 for all three samples, and statistically significant at the 99 percent level. This magnitude of increase suggests the reform led to at least a 50 percent increase in the national literacy rate for women. Estimates for men range from 0.055 to 0.083 , and remain statistically significant for the census and DHS samples.
} 
dependent variable in Panel B of Table 5 is an indicator equal to one if the respondent completed at least eight years of school, and in Panel $\mathrm{C}$ the dependent variable is equal to one if the respondent completed at least nine years of schooling. Estimates are again calculated using the model described in equation (3). Estimates in Panel B demonstrate that the reform increased the likelihood of completing at least eight years of school by between 5.8 and 10.5 percentage points.

The increase in grade eight completion can be thought of as the expected "quantity effect" that has been evident throughout the paper. In both states of the reform, these students then had to pass an exam to be eligible to continue to, and potentially complete, grade nine. If post-reform students perform better on the exam (increased quality), any increase in grade nine completion should be larger than the increase in the grade eight completion rate. If the opposite is true, and the increase is smaller for grade nine, this would be evidence that the quality of the education may be declining. However, this then raises an important secondary question, has completion of grade nine increased due to the reform ("quantity effect" > "quality effect"), or declined ("quantity effect" < "quality effect")? Even in the presence of a decline in quality (a smaller effect on grade nine relative to grade eight), it remains possible that the overall effect of the reform is positive and the increased enrollment outweighs a decline in quality. The estimates in Panel $\mathrm{C}$ of Table 5 help provide insight to the answer for these questions. For both the census and DHS estimates, the increase in grade nine completion is less than the increase in grade eight completion. This suggests a higher failure rate on the post-grade eight exam, a lower quality. The LSMS again diverges, but actually shows a larger increase in grade nine completion. ${ }^{14}$ At the very least, there is no evidence of a decline in quality that is so extreme that it outweighs the increase in the number of students entering and progressing through school. Both the literacy and grade completion estimates provide important suggestive evidence that a sufficient level of quality persists in the post-reform period.

\subsection{Placebo Estimates}

As a general trend, education levels throughout Africa have been increasing in recent years. Although the inclusion of two dimensions of variation helps to alleviate concerns that the estimates for Ethiopia are only capturing this secular increase in education, some level of concern could remain. To address this, an intensity measure is calculated for four additional countries for whom recent data are available, where no reform occurred during the 1990s, but following the equations that define the timing of the Ethiopian reform's implementation. This simulates the same reform measured in Ethiopia being implemented in four alternative settings. Finding similar estimates would suggest that the results shown in this paper are driven

\footnotetext{
${ }^{14}$ Probit estimates across all six grade eight and grade nine estimates are statistically significant at the 99 percent level. Marginal probit point estimates suggest grade eight results between 0.086 and 0.103 , and grade nine estimates ranging between 0.056 and 0.082. All three grade eight estimates are larger, with differences ranging from 0.004 to 0.03 .
} 
by general increases in education that are not specific to Ethiopia. Intensity measures from Kenya (which borders Ethiopia to the southwest), Tanzania, Zambia, and Mali are calculated using census data from each country. ${ }^{15}$ Kenya was chosen due to its proximity to Ethiopia, Mali for its similar pre-1990s education level, and Tanzania and Zambia were added as additional checks that fit the necessary conditions mentioned above. These intensity measures are then paired with the most up to date datasets available, the 2008/9 and 2014 DHS from Kenya, the 2007/8 (AIDS Indicators Survey) and 2010 DHS from Tanzania, the 2010 census from Zambia, and the 2009 census from Mali; equation (3) is used to estimate whether the placebo intensity measures predict increases in schooling similar to those found in Ethiopia. The estimates are shown in Table 6; Panel A includes estimates for a simulated 1993 implementation, and Panel B for a simulated 1995 implementation. Additionally, to mimic the zero intensity measure in Addis Ababa, the intensity measure in each country's urban center is also set equal to zero. ${ }^{16}$ There is no evidence of a large increase in years of schooling linked to the misplaced intensity measures in any of the countries, for either timing of the reform. The largest positive estimate is 0.237 , from the Kenyan DHS; it is about one-fifth of the smallest estimate from Ethiopia, and only 13 percent as large as the corresponding increase using the Ethiopian DHS. For Mali, where an individual born in 1972 averaged only 1.58 years of schooling, the coefficient estimates are large, statistically significant, and negative. This could signify an increased unlikelihood for areas that are in the extremes in regard to education, as Ethiopia was in the early 1990s, to have convergence in education levels without such a significant effort to improve the system. Most importantly, there is no evidence from these regressions that the model is capturing general trends in schooling improvements; large positive estimates were only found in Ethiopia, in the presence of an education reform.

\section{Conclusion}

Using both temporal and geographic variation to identify the effect of the education reform in Ethiopia, the model shows that the removal of school fees led to large increases in schooling. The reform is found to have increased the average Ethiopian's schooling by more than one additional year. The estimates are shown to be robust across a number of specifications and migration adjustments. The reform is also found to have increased literacy rates by nearly 30 percent. The method of identification is replicated in four alternative African countries, countries in which no contemporaneous education reform took place. In none of these countries is there evidence of a similar increase in education, further isolating the Ethiopian reform as the cause of the increase in years of schooling.

The magnitude of the increase in schooling that occurred in Ethiopia due to the reform is difficult to

\footnotetext{
${ }^{15}$ Census data are from Minnesota Population Center's IPUMS (2015).

${ }^{16}$ Estimates allowing variation in the urban centers are shown in Appendix Table A5.
} 
overstate. The reform increased schooling by 50 percent over the baseline level of the 1972 cohort. To put this into perspective, the size of external intervention necessary to cause this kind of national change is unimaginable. In 1995, there were 26 million Ethiopian children under the age of 14. Consider a scenario in which it were possible to construct an education program that would guarantee every student who entered would complete eight years of primary school, and assume that the pre-reform level of schooling was two years, on average. Although the itself program is unrealistic, no program can promise completion, the scale of this type of program would need to be impossibly large. If this program were to be implemented in Ethiopia, and it had a target of increasing schooling by 1.2 years (the median estimate from Table 2), on average, for all 26 million children, the program would have to enroll 5.2 million children. ${ }^{17}$ In other words, the magnitude of the reform that occurred in Ethiopia is equivalent to a program that brings one out of every five children in Ethiopia all the way through eight years of primary school.

This paper presents a strategy, using regularly available data, to identify national level schooling reforms in developing settings. This strategy is applied to Ethiopia, and the estimates indicate that the reform led to significantly more schooling. Initial results also show that the increased quantity of schooling led to higher levels of literacy and ninth grade completion. This is suggestive evidence that the increased enrollments outweighed any potential quality loss in education. Future work can expand on this conclusion by utilizing this method of identification to examine whether the fee removal of the early 1990s, and the increased schooling it generated, led to welfare gains for the people of Ethiopia.

\footnotetext{
${ }^{17}$ This calculation comes from solving for $x$ in the following equation. $3.2=\frac{26-x}{26} \cdot 2+\frac{x}{26} \cdot 8$. The $26-x$ million students not involved in the program remain at two years of school, and $x$ students enter the program and receive eight years of schooling. The goal is to increase the average years of schooling by 1.2 years, from the baseline level of two years, to 3.2 years of school.
} 


\section{References}

Agüero, J. M. and Bharadwaj, P. (2014). Do the More Educated Know More About Health? Evidence from Schooling and HIV Knowledge in Zimbabwe. Economic Development and Cultural Change, 62(3):489-517.

Bertrand, M., Duflo, E., and Mullainathan, S. (2004). How Much Should We Trust Differences-In-Differences Estimates? Quarterly Journal of Economics, 119(1):249-275.

Bleakley, H. (2010). Malaria Eradication in the Americas: A Retrospective Analysis of Childhood Exposure. American Economic Journal: Applied Economics, 2(2):1-45.

Cameron, A. C., Gelbach, J. B., and Miller, D. L. (2008). Bootstrap-Based Improvements for Inference with Clustered Errors. Review of Economics and Statistics, 90(3):414-427.

Deininger, K. (2003). Does Cost of Schooling Affect Enrollment by the Poor? Universal Primary Education in Uganda. Economics of Education Review, 22(3):291-305.

Duflo, E. (2001). Schooling and Labor Market Consequences of School Construction in Indonesia: Evidence from an Unusual Policy Experiment. American Economic Review, 91(4):795-813.

Duflo, E. (2004). The Medium Run Effects of Educational Expansion: Evidence from a Large School Construction Program in Indonesia. Journal of Development Economics, 74(1):163-197.

Elder, T. E. and Lubotsky, D. H. (2009). Kindergarten Entrance Age and Children's Achievement Impacts of State Policies, Family Background, and Peers. Journal of Human Resources, 44(3):641-683.

Food and Agriculture Organization: GeoNetwork (2016). Global Administrative Unit Layers (GAUL).

Grépin, K. A. and Bharadwaj, P. (2015). Maternal Education and Child Mortality in Zimbabwe. Journal of Health Economics, 44:97-117.

Lucas, A. M. (2010). Malaria Eradication and Educational Attainment: Evidence from Paraguay and Sri Lanka. American Economic Journal: Applied Economics, 2(2):46.

Lucas, A. M. (2013). The Impact of Malaria Eradication on Fertility. Economic Development and Cultural Change, 61(3):607-631.

Lucas, A. M. and Mbiti, I. M. (2012a). Access, Sorting, and Achievement: the Short-Run Effects of Free Primary Education in Kenya. American Economic Journal: Applied Economics, 4(4):226-253.

Lucas, A. M. and Mbiti, I. M. (2012b). Does Free Primary Education Narrow Gender Differences in Schooling? Evidence from Kenya. Journal of African Economies, 21(5):691-722. 
McCrary, J. and Royer, H. (2011). The Effect of Female Education on Fertility and Infant Health: Evidence from School Entry Policies Using Exact Date of Birth. American Economic Review, 101(1):158-195.

Ministry of Education (1995). Education Statistics Annual Abstract 1986 EC (1993-94). Technical report, Ministry of Education (Ethiopia), Addis Ababa.

Ministry of Education (1996). Education Statistics Annual Abstract 1987 EC (1994-95). Technical report, Ministry of Education (Ethiopia), Addis Ababa.

Ministry of Education (2000). Education Statistics Annual Abstract 1992 EC (1999-00). Technical report, Ministry of Education (Ethiopia), Addis Ababa.

Minnesota Population Center (2015). International Public Use Microdata Series, International: Version 6.4. [Machine-readable database].

Negash, T. (1996). Rethinking Education in Ethiopia. Uppsala. Nordiska Afrikainstituet.

Ofcansky, T. P. and Berry, L. B. (1993). Ethiopia, A Country Study. Washington DC. Federal Research Division, Library of Congress.

Osili, U. O. and Long, B. T. (2008). Does Female Schooling Reduce Fertility? Evidence from Nigeria. Journal of Development Economics, 87(1):57-75.

Oumer, J. (2009). The challenges of free primary education in Ethiopia. UNESCO: International Institute for Educational Planning.

UNESCO (2007). World Data on Education. Geneva. UNESCO: International Bureau of Education.

World Bank (2009). Abolishing School Fees in Africa: Lessons from Ethiopia, Ghana, Kenya, Malawi, and Mozambique. Washington DC. World Bank.

Zenebe Gebre, T. (2014). Effects of Mother Tongue Education on Schooling and Child Labor Outcomes. Working Paper. 


\section{Figures}

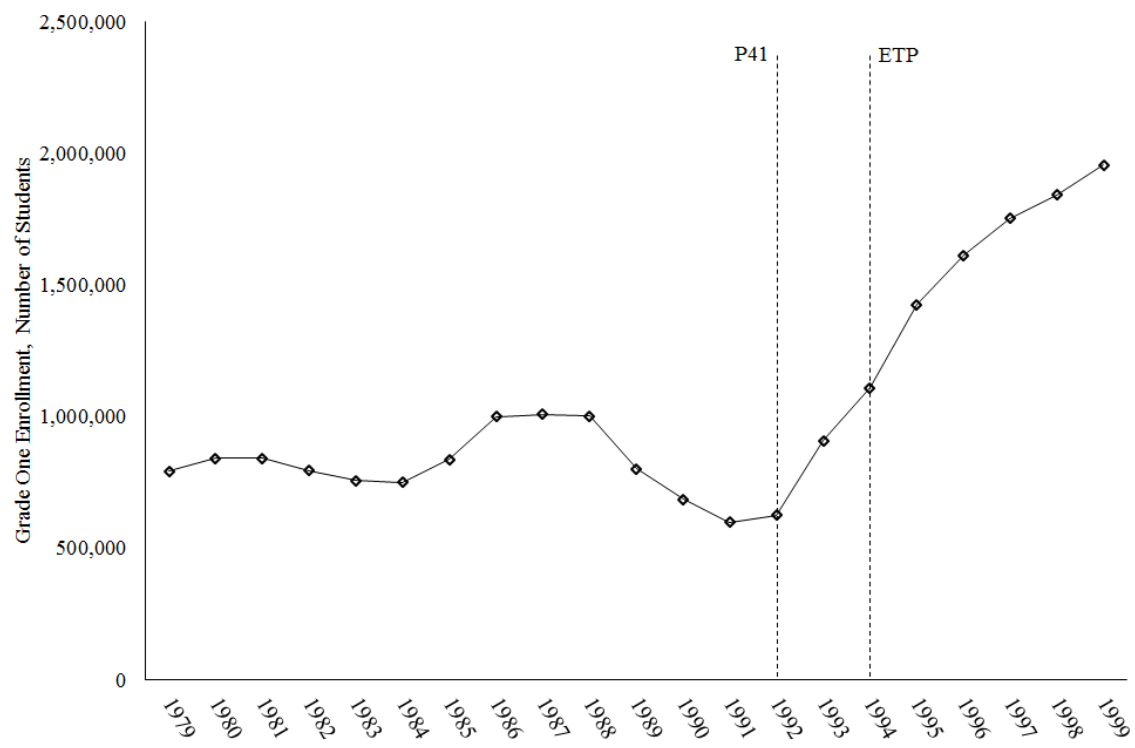

Figure 1: Grade One Enrollment, By Academic Year

Note: P41 refers to Proclamation No. 41, and ETP to the education and Training Policy. Source: UNESCO Institute for Statistics.

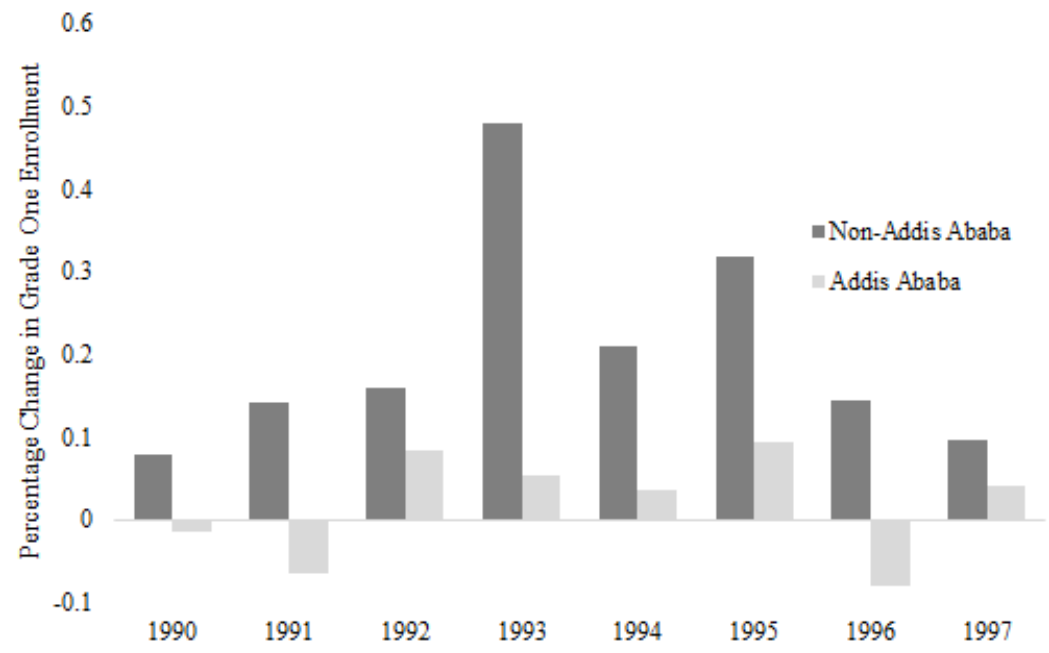

Figure 2: Percentage Change in Grade 1 Enrollment: Addis Ababa vs Rest of Country Source: Ethiopian Ministry of Education (1995; 1996; 2000) 


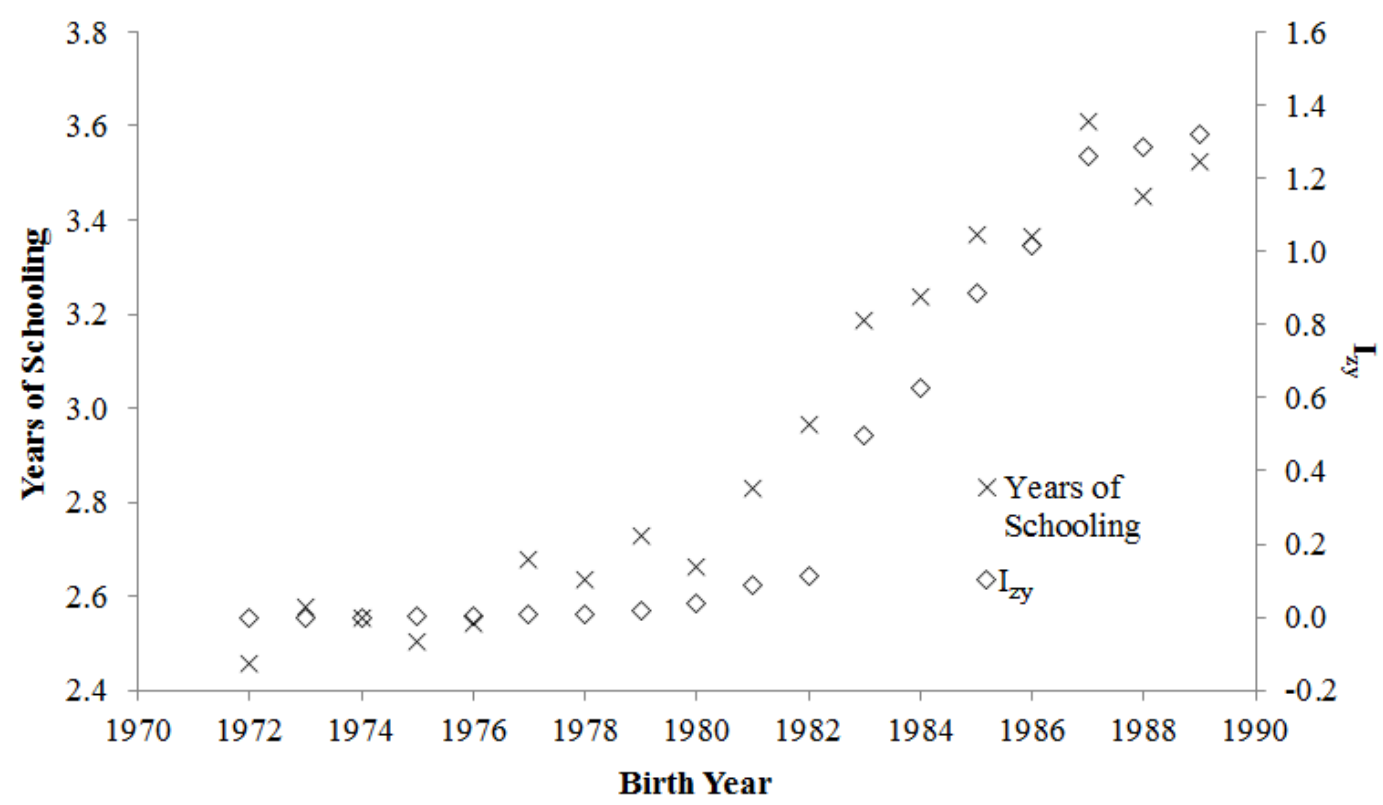

Figure 3: Years of Schooling and $I_{z y}$, by birth year

Note: $I_{z y}$ is the estimated intensity of the reform for individuals in zone $z$, born in year $y$. Years of schooling data are from the 2007 Ethiopian Census (Minnesota Population Center, 2015). 


\section{Tables}

Table 1: Summary Statistics

\begin{tabular}{|c|c|c|c|c|c|c|}
\hline \multirow[b]{2}{*}{ Birth Year } & \multicolumn{2}{|c|}{ Full Sample } & \multicolumn{2}{|c|}{ Female } & \multicolumn{2}{|c|}{ Male } \\
\hline & 1972 & 1989 & 1972 & 1989 & 1972 & 1989 \\
\hline$I_{z y}$ & 0.00 & 1.32 & 0.00 & 1.41 & 0.00 & 1.22 \\
\hline Years of Schooling & 2.03 & 3.41 & 1.16 & 2.94 & 2.98 & 3.89 \\
\hline Literate & 0.35 & 0.59 & 0.21 & 0.51 & 0.50 & 0.66 \\
\hline Completed at Least 8 Years & 0.11 & 0.20 & 0.06 & 0.17 & 0.16 & 0.23 \\
\hline Completed at Least 9 Years & 0.08 & 0.13 & 0.05 & 0.11 & 0.12 & 0.14 \\
\hline
\end{tabular}

Note: $I_{z y}$ is the estimated intensity of the reform for individuals in zone $z$, born in year $y$. All data for schooling variables are from the 2007 Ethiopian Census (Minnesota Population Center, 2015). Literacy, completed at least 8 years, and completed at least 9 years are expressed as fractions of the relevant population group. 
Table 2: Effect of Education Reform on Years of Schooling

\begin{tabular}{|c|c|c|c|}
\hline & $\begin{array}{l}\text { Census } \\
\text { (1) }\end{array}$ & $\begin{array}{c}\text { rs of Schoo } \\
\text { DHS } \\
(2)\end{array}$ & $\begin{array}{c}\text { LSMS } \\
(3)\end{array}$ \\
\hline & \multicolumn{3}{|c|}{ A. Full Sample } \\
\hline$I_{z y}$ & $\begin{array}{c}1.121^{* * *} \\
(0.327)\end{array}$ & $\begin{array}{c}1.767^{* * *} \\
0.233\end{array}$ & $\begin{array}{c}1.251^{* * *} \\
(0.290)\end{array}$ \\
\hline \multirow[t]{2}{*}{$\mathrm{N}$} & $\begin{array}{c}11.77 \\
376,987\end{array}$ & $\begin{array}{c}57.55 \\
20,705\end{array}$ & $\begin{array}{l}18.57 \\
4,571\end{array}$ \\
\hline & \multicolumn{3}{|c|}{ B. Female } \\
\hline$I_{z y}$ & $\begin{array}{c}1.240^{* * *} \\
(0.303)\end{array}$ & $\begin{array}{c}1.822^{* * *} \\
0.246\end{array}$ & $\begin{array}{c}0.895^{*} \\
(0.516)\end{array}$ \\
\hline $\begin{array}{r}\text { F-Stat } \\
\mathrm{N}\end{array}$ & $\begin{array}{c}16.70 \\
199,179\end{array}$ & $\begin{array}{c}54.68 \\
12,598\end{array}$ & $\begin{array}{c}3.01 \\
2,551\end{array}$ \\
\hline \multirow[b]{2}{*}{$I_{z y}$} & \multicolumn{3}{|c|}{ C. Male } \\
\hline & $\begin{array}{c}0.948^{* *} \\
(0.362)\end{array}$ & $\begin{array}{c}1.547^{* * *} \\
0.257\end{array}$ & $\begin{array}{c}1.767^{* * *} \\
(0.308)\end{array}$ \\
\hline F-Stat & 6.87 & 36.29 & 32.91 \\
\hline $\mathrm{N}$ & 177,808 & 8,107 & 2,020 \\
\hline
\end{tabular}

Note: ${ }^{* * *} \mathrm{p}<0.01,{ }^{* *} \mathrm{p}<0.05,{ }^{*} \mathrm{p}<0.1$. The dependent variable is years of schooling. All samples include birth cohorts from 1972 to 1989; in Panel B and Panel C sex specific data are used to calculate the intensity estimated intensity of the reform, $I_{z y}$. All regressions include birth year and zone fixed effects. An indicator equal to one for all male observations is included in Panel A regressions, and DHS estimates, which use data from the 2005 and 2011 surveys, also include a cubic control for age. Census (2007) and LSMS (2014) estimates include only a single survey round, age is therefore jointly determined by birth year and survey year. $I_{z y}$ is set to zero for Addis Ababa, as explained in section 3.2. Each estimate is from a unique regression, weighted using weights provided by the survey, and standard errors are clustered at the zone level. 
Table 3: Effect of Education Reform on Years of Schooling: Alternative Specifications

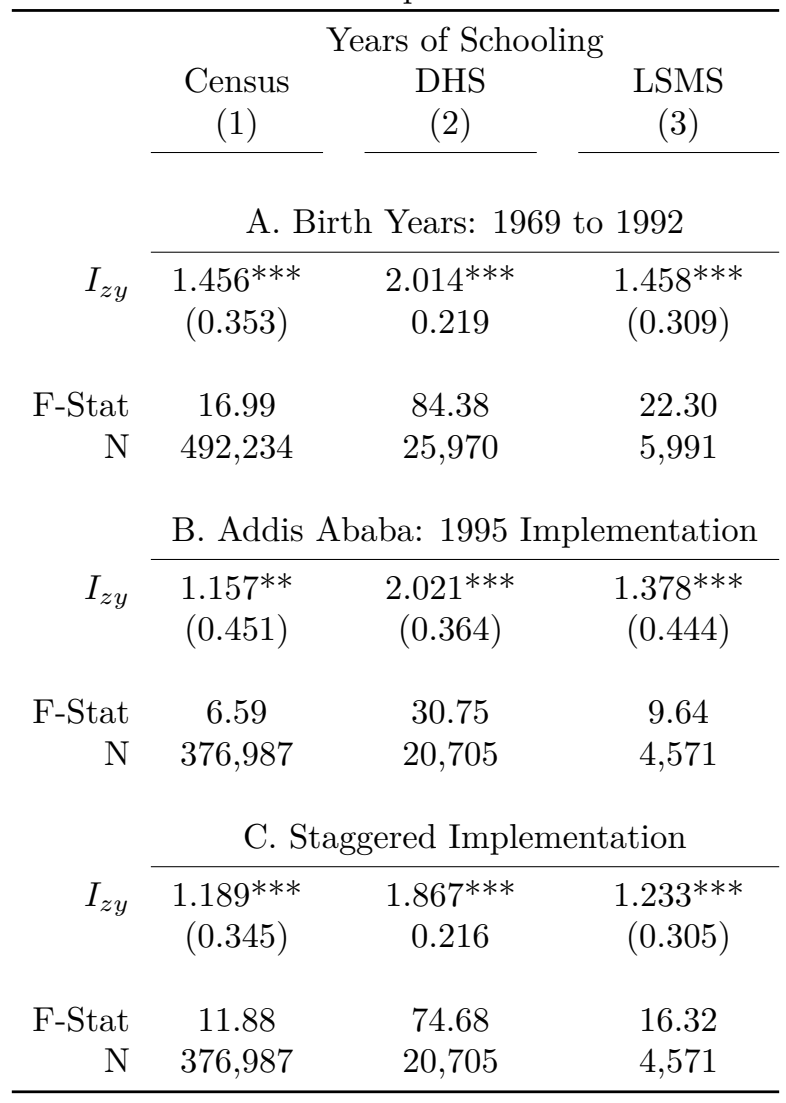

Note: ${ }^{* * *} \mathrm{p}<0.01,{ }^{* *} \mathrm{p}<0.05,{ }^{*} \mathrm{p}<0.1$. The dependent variable is years of schooling. All samples include both male and female observations. All regressions include birth year and zone fixed effects, and an indicator equal to one for observations that are male. DHS estimates, which use data from the 2005 and 2011 surveys, also include a cubic control for age. Census (2007) and LSMS (2014) estimates include only a single survey round, age is therefore jointly determined by birth year and survey year. The sample for Panel A includes cohorts from 1969 to 1972; Panel B and Panel C samples include the 1972 to 1989 cohorts. The estimated intensity of the reform, $I_{z y}$, is fully calculated for the Addis Ababa region in Panel B, and Panel C calculates $I_{z y}$ assuming a gradual implementation as explained in section 3.2. Each estimate is from a unique regression, weighted using weights provided by the survey, and standard errors are clustered at the zone level. 
Table 4: Effect of Education Reform on Years of Schooling: Migration Adjustments

\begin{tabular}{|c|c|c|c|}
\hline & \multicolumn{3}{|c|}{ Years of Schooling (LSMS Only) } \\
\hline & $\begin{array}{c}\text { Birth Region } \\
\text { FE } \\
(1)\end{array}$ & $\begin{array}{l}\text { Only Non- } \\
\text { Movers } \\
(2)\end{array}$ & $\begin{array}{c}\text { Migration } \\
\text { Adjusted } \\
\text { Intensity } \\
\quad(3)\end{array}$ \\
\hline$I_{z y}$ & $\begin{array}{c}1.226^{* * * *} \\
(0.292)\end{array}$ & $\begin{array}{c}1.151^{* * *} \\
(0.417)\end{array}$ & $\begin{array}{c}1.263^{* * *} \\
(0.370)\end{array}$ \\
\hline F-Stat & 17.62 & 7.63 & 11.65 \\
\hline $\mathrm{N}$ & 4,568 & 3,959 & 4,568 \\
\hline
\end{tabular}

Note: $* * * \mathrm{p}<0.01, * * \mathrm{p}<0.05, * \mathrm{p}<0.1$. The dependent variable is years of schooling. The sample includes birth cohorts from 1972 to 1989. All regressions include birth year and zone fixed effects, and an indicator equal to one for observations that are male. The estimate in column (1) also includes region of birth fixed effects. The sample in column (2) only includes respondents living in their region of birth, and column (3) is estimated using a migration adjusted intensity. The estimated intensity of the reform, $I_{z y}$, is set to zero for Addis Ababa, as explained in section 3.2. Each estimate is from a unique regression, weighted using weights provided by the survey, and standard errors are clustered at the zone level. 
Table 5: Effect of Education Reform on Literacy and Completing At Least Eight or Nine Years

\begin{tabular}{|c|c|c|c|}
\hline & $\begin{array}{l}\text { Census } \\
\text { (1) }\end{array}$ & $\begin{array}{c}\text { DHS } \\
(2)\end{array}$ & $\begin{array}{c}\text { LSMS } \\
(3)\end{array}$ \\
\hline \multirow[b]{2}{*}{$I_{z y}$} & \multicolumn{3}{|c|}{ A. Literacy } \\
\hline & $\begin{array}{c}0.086^{* * *} \\
(0.023)\end{array}$ & $\begin{array}{c}0.126^{* * *} \\
(0.027)\end{array}$ & $\begin{array}{c}0.091^{* *} \\
(0.038)\end{array}$ \\
\hline $\mathrm{N}$ & 376,987 & 20,312 & 4,571 \\
\hline \multicolumn{4}{|c|}{ B. Complete At Least Eight Years of School } \\
\hline$I_{z y}$ & $\begin{array}{c}0.079 * * * \\
(0.025)\end{array}$ & $\begin{array}{c}0.105^{* * *} \\
(0.018)\end{array}$ & $\begin{array}{l}0.058^{* *} \\
(0.022)\end{array}$ \\
\hline $\mathrm{N}$ & 376,987 & 20,705 & 4,571 \\
\hline \multicolumn{4}{|c|}{ C. Complete At Least Nine Years of School } \\
\hline$I_{z y}$ & $\begin{array}{c}0.061^{* *} \\
(0.023)\end{array}$ & $\begin{array}{c}0.080 * * * \\
(0.020)\end{array}$ & $\begin{array}{c}0.068^{* *} \\
(0.029)\end{array}$ \\
\hline $\mathrm{N}$ & 376,987 & 20,705 & 4,571 \\
\hline
\end{tabular}

Note: ${ }^{* *} \mathrm{p}<0.01,{ }^{* *} \mathrm{p}<0.05,{ }^{*} \mathrm{p}<0.1$. The dependent variable is an indicator equal to one if the respondent is literate in Panel A, if years of schooling is greater than or equal to eight (Panel B), or nine (Panel C). The sample includes birth cohorts from 1972 to 1989. All regressions include birth year and zone fixed effects, and an indicator equal to one for individuals that are male. DHS estimates, using data from the 2005 and 2011 surveys, also include a cubic control for age. Census (2007) and LSMS (2014) estimates include only a single survey round, age is therefore jointly determined by birth year and survey year. The estimated intensity of the reform, $I_{z y}$, is set to zero for Addis Ababa, as explained in section 3.2. Each estimate is from a unique regression, weighted using weights provided by the survey, and standard errors are clustered at the zone level. 
Table 6: Effect of Education Reform on Years of Schooling: Placebo Estimates

\begin{tabular}{|c|c|c|c|c|}
\hline & \multicolumn{4}{|c|}{ Years of Schooling } \\
\hline & $\begin{array}{l}\text { Kenya } \\
\text { (1) }\end{array}$ & $\begin{array}{c}\text { Tanzania } \\
(2)\end{array}$ & $\begin{array}{c}\text { Zambia } \\
(3)\end{array}$ & $\begin{array}{l}\text { Mali } \\
(4)\end{array}$ \\
\hline \multirow[b]{2}{*}{$I_{z y}$} & \multicolumn{4}{|c|}{ A. 1993 Implementation } \\
\hline & $\begin{array}{l}0.237^{* *} \\
\mathrm{p}=0.048\end{array}$ & $\begin{array}{l}-0.024 \\
(0.357)\end{array}$ & $\begin{array}{l}-0.188 \\
(0.137)\end{array}$ & $\begin{array}{c}-0.777^{* * *} \\
(0.104)\end{array}$ \\
\hline \multirow[t]{2}{*}{$\mathrm{N}$} & 29,410 & 12,803 & 315,846 & 250,506 \\
\hline & \multicolumn{4}{|c|}{ B. 1995 Implementation } \\
\hline$I_{z y}$ & $\begin{array}{c}0.206 \\
\mathrm{p}=0.202\end{array}$ & $\begin{array}{l}-0.091 \\
(0.413)\end{array}$ & $\begin{array}{l}-0.015 \\
(0.184)\end{array}$ & $\begin{array}{c}-0.812^{* * * *} \\
(0.118)\end{array}$ \\
\hline $\mathrm{N}$ & 29,410 & 12,803 & 315,846 & 250,506 \\
\hline
\end{tabular}

Note: ${ }^{* * *} \mathrm{p}<0.01,{ }^{*} \mathrm{p}<0.05,{ }^{*} \mathrm{p}<0.1$. The dependent variable is years of schooling. The sample includes birth cohorts from 1972 to 1989. All regressions include birth year and zone fixed effects, and an indicator equal to one for observations that are male. Kenya data are from 2008/9 and 2014 rounds and Tanzania data are from 2007, 2008 , and 2010 rounds of the DHS; estimates also include a cubic control for age. Zambia and Mali data are from 2010 and 2009 census rounds, respectively. The estimated intensity of the reform, $I_{z y}$, is set to zero for major urban center in each country (Nairobi, Dar es Salaam, Lusaka, Bamako). Each estimate is from a unique regression, weighted using weights provided by the survey, and standard errors are clustered at the zone level. Kenya includes fewer than 50 zones, wildbootstrap p-value is substituted for standard error (Cameron et al., 2008). 


\section{A Appendix}

\section{A.1 Timing and Intensity Calculation: Example of 1995 Implementation}

The following uses a 1995 implementation of the Ethiopian education reform as an example. Appendix Table A6 outlines the year-grade level combinations that are considered to be affected by the reform. The table is organized by birth year, age at the beginning of the calendar year, and grade of attendance if starting and matriculating on time. ${ }^{18}$ Students born in 1987 or later, and starting on time, enter school in the postreform, fee-free, period. However, students entering school before this time must pay the prevailing school fees to enter grade one. These divergent decisions yield two separate probabilities of entering school at a given age, one pre-reform, and one post-reform. School starting age probabilities are calculated using census data for ages 6 to 12 for each zone in Ethiopia; it is assumed that the relative start probabilities across the different ages remain constant. For example, if a student is twice as likely to enter at age seven relative to age six, this ratio is consistent across both states of the reform. For each zone, pre-reform period start probabilities $\left(S_{z, \text { pre }}\right)$ are rescaled to ensure that the sum of the start probabilities for ages 6 to 12 is equal to one minus the fraction of students who never enter school. Post-reform start probabilities $\left(S_{z, \text { post }}\right)$ are scaled by setting the sum of the age 6 to 12 start probabilities equal to one, the maximum potential impact of the reform leading full attendance. The above assumption regarding the relative start age probabilities and these two definitions ensure that the post-reform start probability at any given age, $a$, is larger than the pre-reform start probability $\left(S_{z, p o s t, a}-S_{z, p r e, a}>0\right)$. Note that this leaves a number of students who would enter by age 12 in the post-reform state, but not in the pre-reform state. This will be taken into account in the following equations.

The equations for the calculation of each birth year are listed below. These equations take into account the pre and post start probabilities explained above, and magnitude calculation from equation (1). Any birth year and age combination that would have an individual graduating grade 10 prior to the implementation of the reform, would yield zero benefit from the reform, and is not included in the following equations. From Appendix Table A6, this is analogous to a student being born in 1977 or earlier, and entering grade one no later than 1985. Furthermore, a student born in 1972, that enters school as late as allowed by this model, at age 12, would start grade one in 1985, and therefore not be impacted by the reform,

$$
I_{z, 1972}=0
$$

Then a student born the next year, in 1973, and entering school at age 12 would receive a single year of

\footnotetext{
${ }^{18}$ Ethiopian school begins at the beginning of the Ethiopian year (in September of the Gregorian calendar).
} 
additional schooling from the reform,

$$
I_{z, 1973}=S_{z, p r e, 12} \cdot M_{z}(9)
$$

Those born in 1974 and starting at age 12 would receive two additional years, and starting at 11 would receive one additional year, and this iteration continues in a similar fashion through the 1981 birth year:

$$
\begin{aligned}
& I_{z, 1974}=S_{z, p r e, 12} \cdot M_{z}(8)+S_{z, p r e, 11} \cdot M_{z}(9), \\
& I_{z, 1975}=S_{z, p r e, 12} \cdot M_{z}(7)+S_{z, p r e, 11} \cdot M_{z}(8)+S_{z, p r e, 10} \cdot M_{z}(9), \\
& I_{z, 1976}=S_{z, \text { pre }, 12} \cdot M_{z}(6)+S_{z, \text { pre }, 11} \cdot M_{z}(7)+S_{z, \text { pre }, 10} \cdot M_{z}(8)+S_{z, \text { pre }, 9} \cdot M_{z}(9), \\
& I_{z, 1977}=S_{z, p r e, 12} \cdot M_{z}(5)+S_{z, p r e, 11} \cdot M_{z}(6)+S_{z, p r e, 10} \cdot M_{z}(7)+S_{z, p r e, 9} \cdot M_{z}(8)+S_{z, p r e, 8} \cdot M_{z}(9) \\
& I_{z, 1978}=S_{z, p r e, 12} \cdot M_{z}(4)+S_{z, p r e, 11} \cdot M_{z}(5)+S_{z, p r e, 10} \cdot M_{z}(6)+S_{z, p r e, 9} \cdot M_{z}(7)+S_{z, p r e, 8} \cdot M_{z}(8)+S_{z, p r e, 7} \cdot M_{z}(9), \\
& I_{z, 1979}=S_{z, p r e, 12} \cdot M_{z}(3)+S_{z, p r e, 11} \cdot M_{z}(4)+S_{z, p r e, 10} \cdot M_{z}(5)+S_{z, p r e, 9} \cdot M_{z}(6) \\
& +S_{z, p r e, 8} \cdot M_{z}(7)+S_{z, p r e, 7} \cdot M_{z}(8)+S_{z, p r e, 6} \cdot M_{z}(9), \\
& I_{z, 1980}=S_{z, p r e, 12} \cdot M_{z}(2)+S_{z, p r e, 11} \cdot M_{z}(3)+S_{z, p r e, 10} \cdot M_{z}(4)+S_{z, p r e, 9} \cdot M_{z}(5) \\
& +S_{z, p r e, 8} \cdot M_{z}(6)+S_{z, p r e, 7} \cdot M_{z}(7)+S_{z, p r e, 6} \cdot M_{z}(8), \\
& I_{z, 1981}=S_{z, p r e, 12} \cdot M_{z}(1)+S_{z, p r e, 11} \cdot M_{z}(2)+S_{z, p r e, 10} \cdot M_{z}(3)+S_{z, p r e, 9} \cdot M_{z}(4) \\
& +S_{z, p r e, 8} \cdot M_{z}(5)+S_{z, p r e, 7} \cdot M_{z}(6)+S_{z, p r e, 6} \cdot M_{z}(7) .
\end{aligned}
$$

For the 1981 birth cohort, the latest starters, age 12, begin school in 1986, and still have to make the decision to enter school during the pre-reform period. This changes beginning with the 1982 birth cohort; students who are born in 1982 and enter grade one at age 12 are entering during the post-reform period. Furthermore, there are a set of students who would have entered at earlier ages, 6 to 11, only if fees were removed, but now have the opportunity to enter at age 12 in a fee-free environment. However, many of these students in the delayed entry group may be taking part in other activities that makes school entry infeasible. To take this into account delayed entrants are discounted by the following equation: $\frac{1}{e^{(a-7)}}$. This assumes that entrance for this set of students who would have entered at younger ages in a post-reform state becomes increasingly 
less likely the longer the delay:

$$
\begin{aligned}
I_{z, 1982} & =\left[S_{z, \text { post }, 12}+\frac{1}{e^{12-7}} \sum_{a=6}^{11}\left(S_{\text {post }, a}-S_{\text {pre }, a}\right)\right] M_{z}(0)+S_{z, p r e, 11} \cdot M_{z}(1) \\
& +S_{z, p r e, 10} \cdot M_{z}(2)+S_{z, \text { pre }, 9} \cdot M_{z}(3)+S_{z, p r e, 8} \cdot M_{z}(4)+S_{z, p r e, 7} \cdot M_{z}(5)+S_{z, \text { pre }, 6} \cdot M_{z}(6) .
\end{aligned}
$$

In the 1983 cohort, similar to the 1982 cohort, 11 and 12 year old grade one entrants enter school in the postreform period. Ages 6 through 10 still must make the decision in the pre-reform period, leaving a large stock of potential future entrants. The fraction of remaining entrants is again defined by the $\left(S_{z, p o s t, a}-S_{z, p r e, a}\right)$ difference; the students who would have entered at each age had they been entering in the post-reform period, but had to make the decision pre-reform. However, again the size of this group is discounted to take into account potential productive activity that precludes their ability to enter school at a later time. This pattern is continued through the later cohorts, as well;

$$
\begin{aligned}
& I_{z, 1983}=\left[\sum_{a=11}^{12} S_{z, \text { post }, a}+\frac{1}{e^{11-7}} \sum_{a=6}^{10}\left(S_{z, \text { post }, a}-S_{z, \text { pre }, a}\right)\right] M_{z}(0) \\
& +S_{z, p r e, 10} \cdot M_{z}(1)+S_{z, p r e, 9} \cdot M_{z}(2)+S_{z, p r e, 8} \cdot M_{z}(3)+S_{z, p r e, 7} \cdot M_{z}(4)+S_{z, p r e, 6} \cdot M_{z}(5), \\
& I_{z, 1984}=\left[\sum_{a=10}^{12} S_{z, p o s t, a}+\frac{1}{e^{10-7}} \sum_{a=6}^{9}\left(S_{z, \text { post }, a}-S_{z, p r e, a}\right)\right] M_{z}(0) \\
& +S_{z, p r e, 9} \cdot M_{z}(1)+S_{z, p r e, 8} \cdot M_{z}(2)+S_{z, p r e, 7} \cdot M_{z}(3)+S_{z, p r e, 6} \cdot M_{z}(4), \\
& I_{z, 1985}=\left[\sum_{a=9}^{12} S_{z, \text { post }, a}+\frac{1}{e^{9-7}} \sum_{a=6}^{8}\left(S_{z, \text { post }, a}-S_{z, p r e, a}\right)\right] M_{z}(0) \\
& +S_{z, p r e, 8} \cdot M_{z}(1)+S_{z, p r e, 7} \cdot M_{z}(2)+S_{z, p r e, 6} \cdot M_{z}(3), \\
& I_{z, 1986}=\left[\sum_{a=8}^{12} S_{z, p o s t, a}+\frac{1}{e^{8-7}} \sum_{a=6}^{7}\left(S_{z, p o s t, a}-S_{z, p r e, a}\right)\right] M_{z}(0)+S_{z, p r e, 7} \cdot M_{z}(1)+S_{z, p r e, 6} \cdot M_{z}(2), \\
& I_{z, 1987}=\left[\sum_{a=7}^{12} S_{z, p o s t, a}+\frac{1}{e^{7-7}}\left(S_{z, p o s t, 6}-S_{z, p r e, 6}\right)\right] M_{z}(0)+S_{z, p r e, 6} \cdot M_{z}(1), \\
& I_{z, 1988}=\left[\sum_{a=6}^{12} S_{z, \text { post }, a}\right] M_{z}(0)=M_{z}(0) .
\end{aligned}
$$

For the 1989 birth cohort, all individuals, even the early starters, enter school completely in the post-reform period. 


\section{A.2 Appendix - Tables}

Table A1: Effect of Education Reform on Years of Schooling: Sex Specific Alternative Specifications

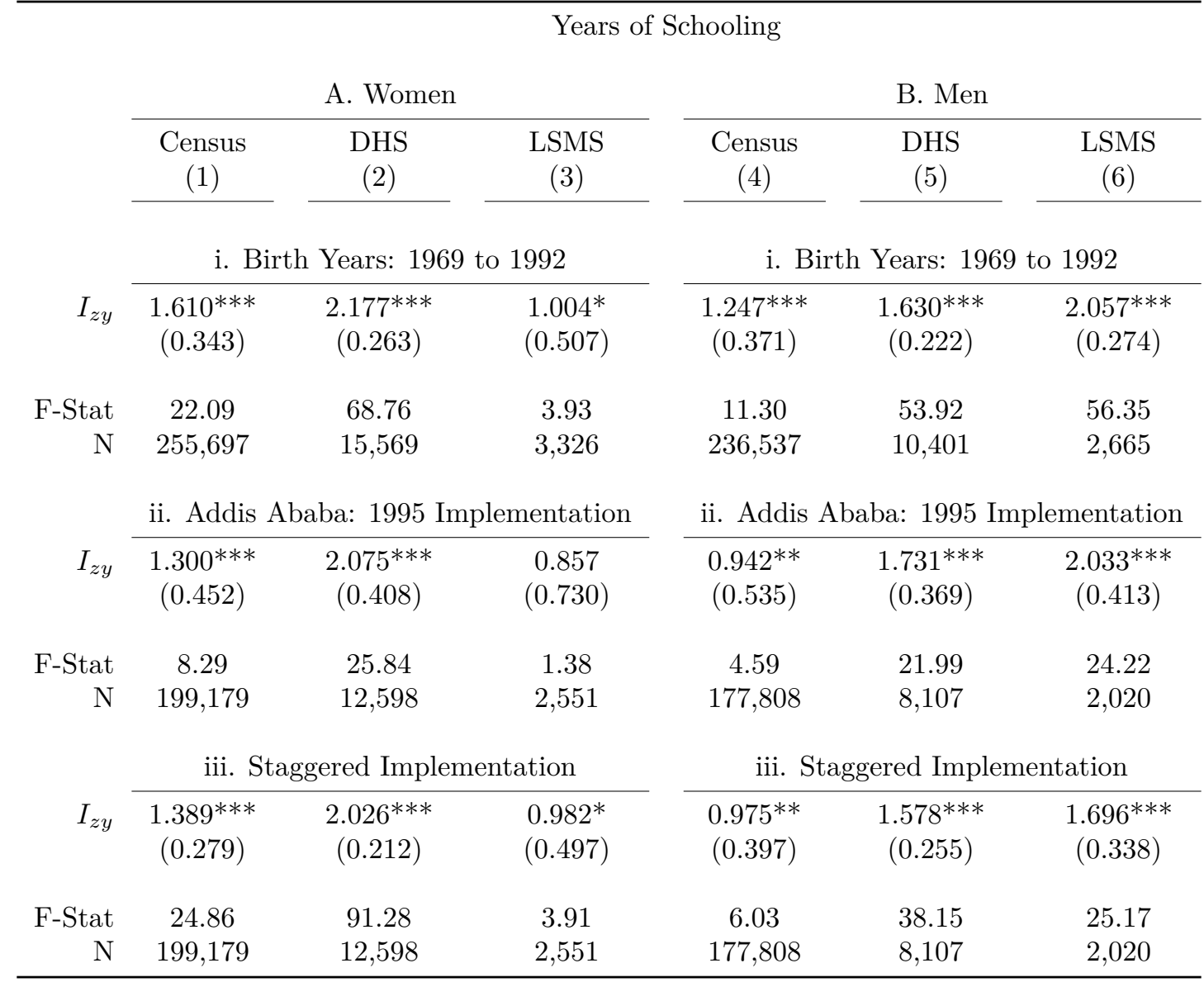

Note: ${ }^{* * *} \mathrm{p}<0.01,{ }^{* *} \mathrm{p}<0.05,{ }^{*} \mathrm{p}<0.1$. The dependent variable is years of schooling. The estimated intensity measure, $I_{z y}$, is calculated with the relevant sex specific data for Panel A (female) and Panel B (male). All regressions include birth year and zone fixed effects. DHS estimates, which use data from the 2005 and 2011 surveys, also include a cubic control for age. Census (2007) and LSMS (2014) estimates include only a single survey round; age is therefore jointly determined by birth year and survey year. Samples in Panel ii and Panel iii include birth cohorts from 1972 to 1989; the sample in Panel i expands the sample to cohorts from 1969 to 1972. Panel ii fully calculates $I_{z y}$ for the Addis Ababa region, and Panel iii calculates $I_{z y}$ assuming a gradual implementation as explained in section 3.2. Each estimate is from a unique regression, weighted using weights provided by the survey, and standard errors are clustered at the zone level. 
Table A2: Effect of Education Reform on Years of Schooling: All DHS Observations

\begin{tabular}{|c|c|c|c|}
\hline & Year & f Schooling & $\mathrm{HS})$ \\
\hline & $\begin{array}{l}\text { Full } \\
(1)\end{array}$ & $\begin{array}{l}\text { Women } \\
(2)\end{array}$ & $\begin{array}{c}\text { Men } \\
(3)\end{array}$ \\
\hline$I_{z y}$ & $\begin{array}{c}1.500^{* * *} \\
(0.276)\end{array}$ & $\begin{array}{c}1.602^{* * *} \\
(0.262)\end{array}$ & $\begin{array}{c}1.228^{* * *} \\
(0.316)\end{array}$ \\
\hline F-Stat & 29.43 & 37.36 & 15.14 \\
\hline $\mathrm{N}$ & 27,425 & 17,588 & 9,837 \\
\hline $\begin{array}{l}\text { Note: } * * * \\
\text { variable is } \\
\text { cohorts fro } \\
\text { the estima } \\
\text { the relevar } \\
\text { year and z } \\
\text { indicator e } \\
\text { in the coll } \\
\text { report not } \\
\text { the origina } \\
\text { explained } \\
\text { regression, } \\
\text { and stand }\end{array}$ & $\begin{array}{l}\mathrm{p}<0.01,{ }^{* *} \mathrm{p} \\
\text { years of scho } \\
\mathrm{m} 1972 \text { to } 19 \\
\text { ted intensity } \\
\mathrm{t} \text { sex specific } \\
\text { ne fixed effect } \\
\text { qual to one fo } \\
\text { mn (1) regres } \\
\text { knowing thei } \\
\text { l sample. } I_{z y} \\
\text { in section } 3.2 \\
\text { weighted usin } \\
\text { ird errors are }\end{array}$ & $\begin{array}{l}.05,{ }^{*} \mathrm{p}<0.1 \\
\text { g. The sam } \\
\text { in column }(2 \\
\text { asure, } I_{z y} \text {, is } \\
\text { a. All regress } \\
\text { and a cubic cc } \\
\text { male observ } \\
\text { n. All DHS } \\
\text { act year of b } \\
\text { et to zero for } \\
\text { ach estimate } \\
\text { reights provic } \\
\text { stered at the }\end{array}$ & $\begin{array}{l}\text { e dependent } \\
\text { acludes birth } \\
\text { d column (3) } \\
\text { ulated using } \\
\text { include birth } \\
\text { l for age. An } \\
\text { s is included } \\
\text { rvations that } \\
\text { are added to } \\
\text { lis Ababa, as } \\
\text { om a unique } \\
\text { y the survey, } \\
\text { e level. }\end{array}$ \\
\hline
\end{tabular}

Table A3: Effect of Education Reform on Years of Schooling: Migration Adjustments with 1995 Implementation in Addis Ababa

\begin{tabular}{|c|c|c|c|}
\hline & $\begin{array}{l}\text { Years of } \\
\text { Birth Region } \\
\text { FE } \\
(1)\end{array}$ & $\begin{array}{l}\text { Only Non- } \\
\text { Movers } \\
(2)\end{array}$ & $\begin{array}{l}\text { Mnly) } \\
\text { Migration } \\
\text { Adjusted } \\
\text { Intensity } \\
\quad(3)\end{array}$ \\
\hline$I_{z y}$ & $\begin{array}{c}1.358 * * * \\
(0.446)\end{array}$ & $\begin{array}{c}1.203^{* *} \\
(0.573)\end{array}$ & $\begin{array}{c}1.348^{* *} \\
(0.514)\end{array}$ \\
\hline $\begin{array}{r}\text { F-Stat } \\
\mathrm{N}\end{array}$ & $\begin{array}{c}9.26 \\
4,568\end{array}$ & $\begin{array}{c}4.41 \\
3,959\end{array}$ & $\begin{array}{c}6.87 \\
4,568\end{array}$ \\
\hline $\begin{array}{l}\text { Note: } * * * \\
\text { years of sc } \\
1989 \text {. All } \\
\text { indicator } \\
\text { also incluc } \\
\text { responden } \\
\text { a migratic } \\
I_{z y} \text {, is ful } \\
\text { tation. Ea } \\
\text { weights pl }\end{array}$ & $\begin{array}{l}<0.01, * * \mathrm{p}<0.05 \\
\text { oling. The samp } \\
\text { gressions include } \\
\text { ual to one for ob } \\
\text { region of birth } \mathrm{f} \\
\text { living in their } \mathrm{r} \\
\text { adjusted intensi } \\
\text { calculated for } \\
\text { estimate is fron } \\
\text { ided by the surv }\end{array}$ & $\begin{array}{l}\mathrm{p}<0.1 \text {. The de } \\
\text { cludes birth co } \\
\text { th year and zo } \\
\text { ations that are } \\
\text { effects. Colum } \\
\text { n of birth, and } \\
\text { The estimated } \\
\text { Ababa using } \\
\text { unique regressi } \\
\text { and standard }\end{array}$ & $\begin{array}{l}\text { ent variable is } \\
\text { s from } 1972 \text { to } \\
\text { xed effects, an } \\
\text { le; column (1) } \\
\text { only includes } \\
\text { amn (3) using } \\
\text { asity measure, } \\
95 \text { implemen- } \\
\text { veighted using } \\
\text { are clustered }\end{array}$ \\
\hline
\end{tabular}




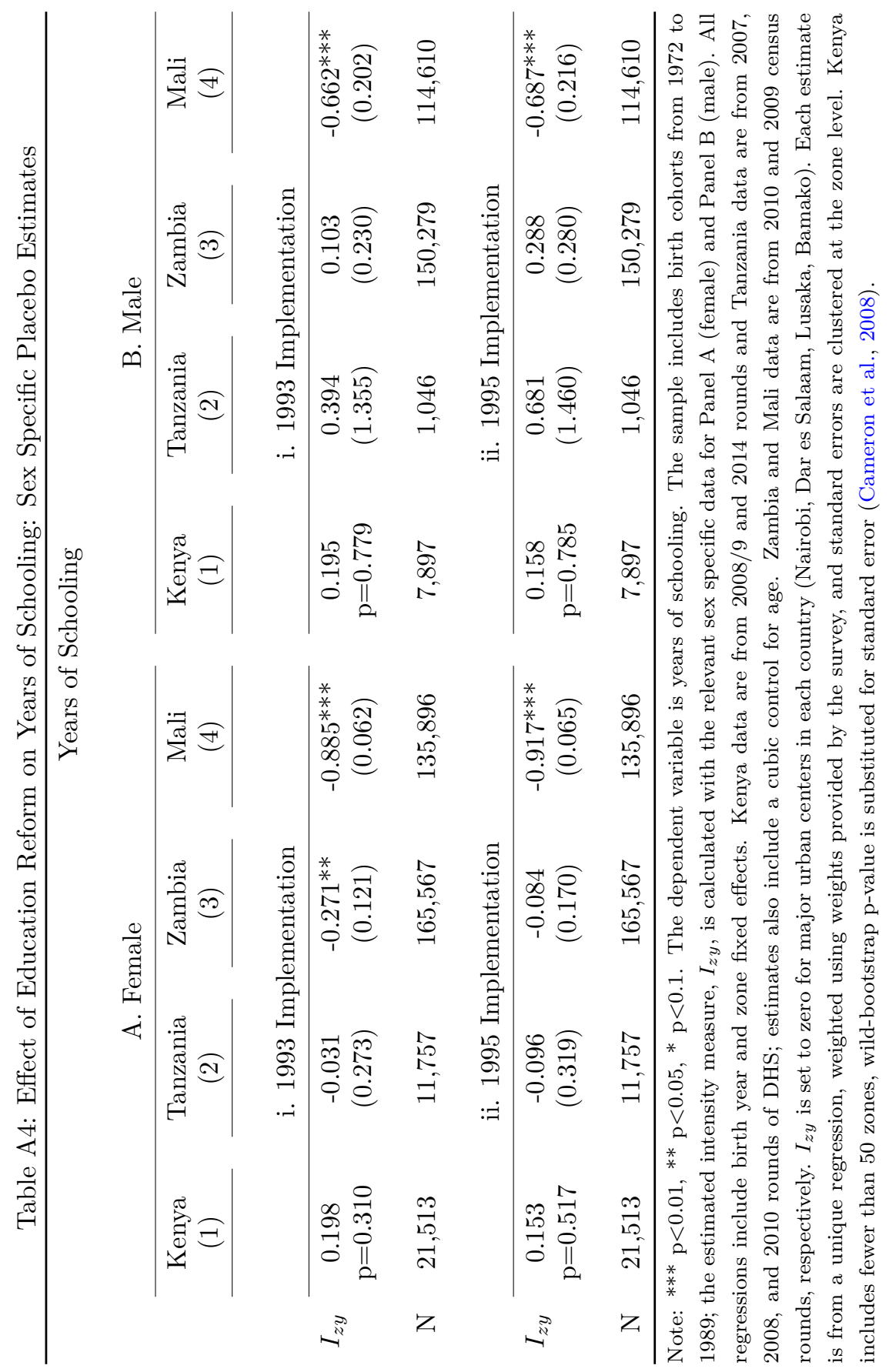


Table A5: Effect of Education Reform on Years of Schooling: Placebo Estimates with Population Center Variation

\begin{tabular}{|c|c|c|c|c|}
\hline & \multicolumn{4}{|c|}{ Years of Schooling } \\
\hline & $\begin{array}{l}\text { Kenya } \\
(1)\end{array}$ & $\begin{array}{c}\text { Tanzania } \\
(2)\end{array}$ & $\begin{array}{c}\text { Zambia } \\
(3)\end{array}$ & $\begin{array}{l}\text { Mali } \\
(4)\end{array}$ \\
\hline \multirow[b]{2}{*}{$I_{z y}$} & \multicolumn{4}{|c|}{ A. 1993 Implementation } \\
\hline & $\begin{array}{c}0.314^{*} \\
\mathrm{p}=0.070\end{array}$ & $\begin{array}{c}-1.117^{* * *} \\
(0.391)\end{array}$ & $\begin{array}{c}-0.026 \\
(0.211)\end{array}$ & $\begin{array}{c}-1.371^{* * *} \\
(0.264)\end{array}$ \\
\hline \multirow[t]{2}{*}{$\mathrm{N}$} & 29,410 & 12,803 & 315,846 & 250,506 \\
\hline & \multicolumn{4}{|c|}{ B. 1995 Implementation } \\
\hline$I_{z y}$ & $\begin{array}{c}0.264 \\
p=0.228\end{array}$ & $\begin{array}{c}-1.334^{* * *} \\
(0.411)\end{array}$ & $\begin{array}{c}0.292 \\
(0.188)\end{array}$ & $\begin{array}{c}-1.423^{* * *} \\
(0.315)\end{array}$ \\
\hline $\mathrm{N}$ & 29,410 & 12,803 & 315,846 & 250,506 \\
\hline
\end{tabular}

Note: ${ }^{* * *} \mathrm{p}<0.01,{ }^{*} \mathrm{p}<0.05,{ }^{*} \mathrm{p}<0.1$. The dependent variable is years of schooling. The sample includes birth cohorts from 1972 to 1989. All regressions include birth year and zone fixed effects. Kenya data are from 2008/9 and 2014 rounds and Tanzania data are from 2007, 2008, and 2010 rounds of DHS; estimates also include a cubic control for age. Zambia and Mali data are from 2010 and 2009 census rounds, respectively. The estimated intensity of the reform, $I_{z y}$, is fully calculated for all districts. Each estimate is from a unique regression, weighted using weights provided by the survey, and standard errors are clustered at the zone level. Kenya includes fewer than 50 zones, wildbootstrap p-value is substituted for standard error (Cameron et al., 2008). 


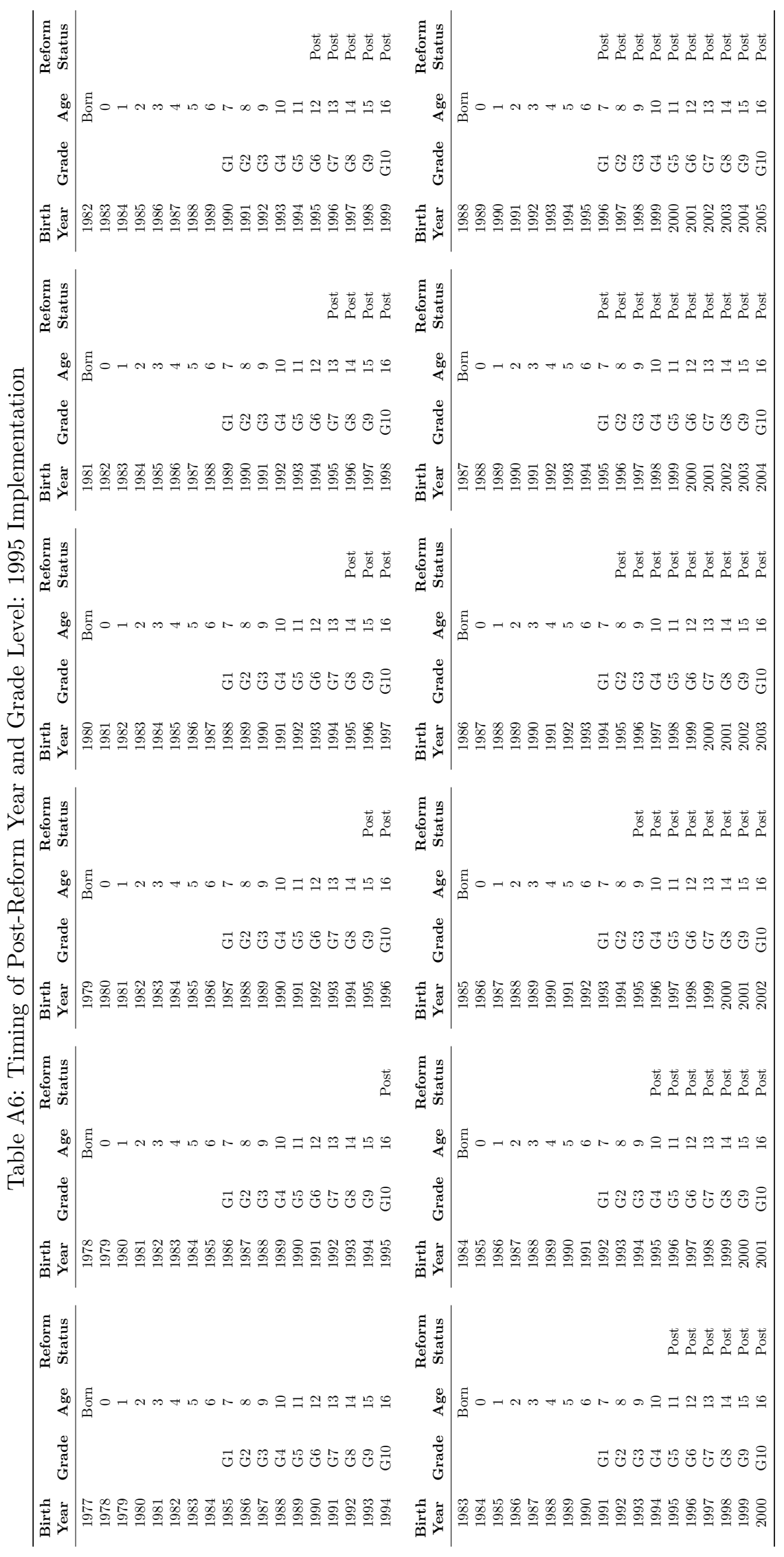

